\title{
Impact of prior cancer history on the survival of patients with larynx cancer
}

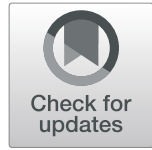

Kaiquan Zhu, Renyu Lin, Ziheng Zhang, Huanqi Chen and Xingwang Rao*

\begin{abstract}
Background: Patients with a prior history of cancer are commonly excluded from clinical trial. Increasing number of studies implied that a prior cancer did not adversely affect the clinical outcome among various types of cancer patients. However, the impact of prior cancer on survival of larynx cancer patients remains largely unknown. The aim of this study was to evaluate the prevalence of prior cancer and assess its impact on survival of patients diagnosed with larynx cancer.

Methods: Patients with larynx cancer as the first or second primary malignancy diagnosed from 2004 to 2015 were extracted from the Surveillance, Epidemiology, and End Results (SEER) database. Propensity score matching (PSM) was conducted to balance baseline characteristics. Kaplan-Meier method, multivariate Cox proportional hazard model, and multivariate competing risk model were performed for survival analysis.

Results: A total of 24,812 eligible patients with larynx cancer were included in the study, wherein a total of 2436 patients (9.8\%) had a prior history of cancer. Prostate (36\%), lung and bronchus (10\%), urinary bladder (7\%), and breast (6\%) were the most common types of prior cancer. A prior cancer history served as a risk factor for overall survival (AHR $=1.30 ; 95 \% \mathrm{Cl}[1.21-1.41] ; P<0.001)$ but a protective factor for cancer-specific mortality $(A H R=0.83$; $95 \% \mathrm{Cl}[0.72-0.94] ; P=0.004)$ in comparison with those without prior cancer. The subgroup analysis showed that a prior history of cancer adversely affected overall survival of patients with larynx cancer in most subgroups stratified by timing and types of prior cancer, as well as by different clinicopathologic features.
\end{abstract}

Conclusion: Our study indicated an adverse survival impact of a prior history of cancer on patients with larynx cancer. Except for a few particular prior cancer, clinical trials should be considered prudently for laryngeal cancer patients with prior cancers.

Keywords: Larynx cancer, Prior cancer, Survival, SEER, Trial eligibility

\section{Background}

Over the past thirty years, the population of cancer survivors is growing rapidly in the United States. A previous report revealed that there were three million cancer survivors in the United States in 1971, which, however, soared to a total of 11.7 million in the year 2007, indicating an approximately four-fold increase growth rate [1]. More importantly, the number has been on the rise

\footnotetext{
*Correspondence: xingwang_rao@126.com

Department of otolaryngology, The First Affiliated Hospital of Wenzhou

Medical University, Wenzhou, Zhejiang Province 325000, P. R. China
}

partly due to the aging population and the significant advances made in the early detection and treatment of cancer [2,3]. There were about two-thirds of cancer survivors who had survived for more than five years after the initial diagnosis [2], which caused an increased risk for developing multiple primary cancer [4-6].

Larynx cancer is the second most common cancer in the head and neck region, accounting for an estimated 13,150 new cases and a total of 3710 deaths in the United States [7]. Recently, along with the increased number of cancer survivors, larynx cancer was frequently diagnosed as the second primary malignant

(c) The Author(s). 2020 Open Access This article is licensed under a Creative Commons Attribution 4.0 International License, which permits use, sharing, adaptation, distribution and reproduction in any medium or format, as long as you give appropriate credit to the original author(s) and the source, provide a link to the Creative Commons licence, and indicate if changes were made. The images or other third party material in this article are included in the article's Creative Commons. licence, unless indicated otherwise in a credit line to the material. If material is not included in the article's Creative Commons licence and your intended use is not permitted by statutory regulation or exceeds the permitted use, you will need to obtain permission directly from the copyright holder. To view a copy of this licence, visit http://creativecommons.org/licenses/by/4.0/ The Creative Commons Public Domain Dedication waiver (http://creativecommons.org/publicdomain/zero/1.0/) applies to the data made available in this article, unless otherwise stated in a credit line to the data. 
neoplasms (SPMs). Unfortunately, those patients with a prior cancer history were ruled out by most of the clinical trials concentrating on larynx cancer [8-12]. Given the sizable number of these patients, the exclusion criterion may limit the accuracy and generalizability of clinical trials, thus leaving some essential clinical questions unanswered [13, 14]. This stringent criterion is mainly due to concerns regarding prior treatment interference and its survival impact, though little evidence supports this assumption. Also, several previous retrospective studies reported that a prior cancer history did not adversely affect clinical outcomes of patients with various cancer [15-17]. However, since few studies have focused on the clinical outcome of patients with secondary laryngeal cancer, much is unknown as to if a prior cancer history impacts the clinical outcome of laryngeal cancer patients.

Therefore, to address this issue, the current study aimed to determine the impact of prior cancers on clinical outcomes among patients who developed larynx cancer as a second primary malignancy by using the Surveillance, Epidemiology, and End Results (SEER) database. We also hope the findings of this study may provide potential insight into the clinical management of laryngeal cancer patients with a prior cancer history.

\section{Methods}

\section{Database and case selection}

Data was obtained from the custom SEER database [Incidence- SEER 18 Regs Custom Data (with additional treatment fields), Nov 2018 Sub (1975-2016 varying)], which collected cancer data that covers approximately $28 \%$ of the United States population [18]. The SEER*Stat software version 8.3.6.1 (National Cancer Institute, USA) was utilized to access the data from SEER database. The patients who were diagnosed with larynx cancer (site code C32.0, C32.1, C32.2 C32.3, and C32.8) from 2004 to 2015 were extracted from the database. Only patients with only one primary tumor or patients who had exactly one prior malignancy were included. In order to exclude the synchronous primary cancers, a 2-month time interval was required between the prior cancer diagnosis and the second larynx cancer diagnosis. Other exclusion criteria were listed as follows: 1) patients with incomplete follow-up; 2) patients whose diagnosis was made at autopsy or based on a death certificate; 3) and patients who had unknown information of diagnosed months. Finally, a total of 24,812 eligible patients were included in this study. The detail flowchart of case selection can be seen in Fig. S1.

\section{Covariates}

The analysis involved multiple variables including demographic characteristics (year of diagnosis, age at diagnosis, gender, race, and marital status), disease characteristics (histologic grade, AJCC stage, and prior cancer type), and treatment characteristics (surgery, radiotherapy and chemotherapy). Specially, the continuous variables, age at diagnosis, were transformed into categorical variables $(<45,45-64$, and $>64)$. Marital status including divorced, single, widowed, separated and domestic partner were classified into other status. The history of prior cancer was determined from the SEER sequence numbers code, which records the sequence of all malignancies occurred over the lifetime of the patient. Based on the recode of year of diagnosis and month of diagnosis, we calculated the time interval between two cancer record by subtracting the diagnosis date of the prior cancer from that of index larynx cancer. Vital status record were utilized to calculate the overall survival (OS). In addition, patients who died directly from larynx cancer were recorded as dead (attributable to this cancer) based on the code of cause-specific death classification in the SEER program. Alive or dead from a cause other than larynx cancer were considered as a competing risk event and censored at the time of the event. Hence, the SEER cause-specific death classification was utilized to calculate the larynx cancer-specific mortality (LCSM).

\section{Statistical analysis}

Based on the SEER sequence number recode, we categorized the patients into two groups, including patients with primary larynx cancer (PLC) and patients having larynx cancer as the second primary malignancy (SLC). Descriptive statistic was utilized to summarize the demographic and clinical factors of these two groups of patients. Clinicopathologic characteristics between patients with or without prior cancer were compared using Pearson chi-square tests. The Log-rank test or Gray's test was used to compare differences of OS and LCSM between patients with or without prior cancer record before and after propensity score matching (PSM). The detailed description for PSM could be seen in Supplementary material. The multivariate Cox regression analysis was used to identify whether the prior cancer history was an independent prognostic factor for OS. Meanwhile, multivariable Fine and Gray competing-risk regression model was built to analyze the impact of prior cancer history on LCSM. The common demographic and clinical characteristics, including age, gender, race, marital status, AJCC stage (sixth edition), grade, and treatment modalities (surgery, chemotherapy, and radiotherapy) were included as covariates.

Descriptive statistic, Pearson Chi-square test, and Cox proportional hazards model were performed using SPSS 24.0 (IBM Corp). Kaplan-Meier plot, log-rank test, and 
the Fine and Gray competing-risk regression model were plotted or conducted by using $\mathrm{R}$ software version 4.0.0.

\section{Results}

\section{Baseline characteristics}

A total of 24,812 eligible patients with larynx cancer were included, of whom $2436(9.8 \%)$ had a history of prior cancer. $67.3 \%$ of the patients had their prior cancer identified as AJCC stage I-II. The median time interval (IQR) between the index larynx cancer and the prior cancer was 63 (29-112) months, and the median followup (IQR) was 26 (11-58), starting from the diagnosis of larynx cancer (Table 1). After adjusted for propensity scores, all variables were well-balanced between patients with or without prior cancer (Table 2).

Prostate (36\%), lung and bronchus (10\%), urinary bladder $(7 \%)$, and breast (6\%) were the most common prior cancer types (Table 3). The overall survival (OS) varied significantly among larynx cancer patients who had different types of prior cancer $(P<0.001)$. Patients with prior lung cancer had the shortest OS, whereas those with prior prostate or colon cancer had a relatively good prognosis (Fig. 1).

\section{Impact of prior cancer history on the survival of larynx cancer patients}

As shown in Fig. 2a and Fig. S3A, patients with prior cancer history had significant inferior OS but decreased LCSM compared to those patients without prior cancer. After adjusted for propensity scores, a similar result was shown in Fig. $2 \mathrm{~b}$ and Fig. S3B. Then, subgroup analyses were conducted for patients stratified by timing and types of prior cancer. Figure 3 indicated that patients with a prior cancer diagnosis had significant adverse impact on OS regardless of the time interval between the index larynx cancer and the prior cancer diagnosis. For LCSM, our results showed that patients with a prior cancer history had a marginal or significantly decreased LCSM compared to patients without a history of prior cancer, especially when the time interval was larger than 12 months (Fig. S4). As shown in Fig. 4 and Fig. S5, the impact of prior cancer on the OS and LCSM of larynx cancer patients varied extensively with different cancer types. The result showed that a prior prostate cancer diagnosis had no significant impact on the OS of larynx cancer patients, but exerted a significant protective factor for LCSM (Fig. 4a and Fig. S5A). On the contrary, larynx cancer patients with a prior lung or breast cancer diagnosis had dramatically inferior OS as compared to patients without a prior history of cancer, but not the LCSM (Fig. 4b and d, and Fig. S5B and D). Moreover, larynx cancer patients with a prior history of urinary bladder cancer or colon cancer both had similar OS and LCSM in comparison with patients without a prior cancer history (Fig. 4c and f, and Fig. S5C and F). Besides, a prior larynx cancer showed an inferior OS as well as increased LCSS, as compared to patients without a prior cancer diagnosis (Fig. 4e and Fig. S5E).

As shown in Table 4, the multivariate Cox analysis for patients' OS indicated that a history of prior cancer was an independent risk factor for OS (AHR $=1.30$; 95\% CI [1.21-1.41]). On the contrary, the multivariate competitive risk analysis showed that a history of prior cancer was an independent protective factor for LCSM (AHR = 0.83; 95\% CI [0.72-0.94]). This data, combined with the OS result from the Cox analysis, suggested that patients with prior history of cancer were more likely to die from non-larynx cause than those without prior cancer. In addition, the Cox model suggested that a married status and treatment modalities including surgery, and radiotherapy were significant protective factors for OS of larynx patients with prior cancer history, whereas later AJCC stage, and high histological grade were risk factors. The competing risk model determined that a

Table 1 Summary description of demographic and clinical factors $(N=2436)$

\begin{tabular}{|c|c|c|c|}
\hline \multicolumn{2}{|c|}{ At prior cancer diagnosis } & \multicolumn{2}{|c|}{ At larynx cancer diagnosis } \\
\hline Variable & Value & Variable & Value \\
\hline \multicolumn{2}{|l|}{ Age, years } & \multicolumn{2}{|l|}{ Age, years } \\
\hline Mean & 64.7 & Mean & 71.3 \\
\hline Median (IQR) & $66(58-72)$ & Median (IQR) & $72(64-79)$ \\
\hline \multicolumn{2}{|l|}{ AJCC stage, n (\%) } & \multicolumn{2}{|c|}{ AJCC stage, n (\%) } \\
\hline$|-| \mid$ & $803(67.3)$ & H-II & $1321(54.2)$ \\
\hline III-IV & $263(10.8)$ & III-IV & $930(38.2)$ \\
\hline Unknown & $1370(21.9)$ & Unknown & $185(7.6)$ \\
\hline \multicolumn{2}{|c|}{ Interval between diagnoses, months } & \multicolumn{2}{|c|}{ Follow up from diagnosis of larynx cancer, months } \\
\hline Mean & 79.6 & Mean & 38.5 \\
\hline Median (IQR) & $63(29-112)$ & Median (IQR) & $26(11-58)$ \\
\hline
\end{tabular}


Table 2 Baseline characteristics of patients with larynx cancer in the original/matched data sets $(\mathrm{N}=24,812)$

\begin{tabular}{|c|c|c|c|c|c|c|}
\hline \multirow[t]{2}{*}{ Characteristics } & \multicolumn{3}{|l|}{ Original data set } & \multicolumn{3}{|l|}{ Matched data set } \\
\hline & $\begin{array}{l}\text { No prior cancer } \\
N=22,376(\%)\end{array}$ & $\begin{array}{l}\text { With prior cancer } \\
\mathrm{N}=2436(\%)\end{array}$ & $P$ value & $\begin{array}{l}\text { No prior cancer } \\
\mathrm{N}=2436(\%)\end{array}$ & $\begin{array}{l}\text { With prior cancer } \\
\mathrm{N}=2436(\%)\end{array}$ & $P$ value \\
\hline Age (years), mean (SD) & $63.6(11.6)$ & $71.3(10.1)$ & $<.001$ & $68.4(10.0)$ & $71.3(10.1)$ & 0.025 \\
\hline Year of diagnose(\%) & & & 0.001 & & & 0.643 \\
\hline 2004-2009 & $10,484(46.9)$ & $1056(43.3)$ & & $1040(42.7)$ & $1056(43.3)$ & \\
\hline 2010-2015 & $11,892(53.1)$ & $1380(56.7)$ & & $1396(57.3)$ & $1380(56.7)$ & \\
\hline Race & & & 0.025 & & & 0.069 \\
\hline White & $17,878(79.9)$ & 1981 (81.3) & & 2019 (82.9) & $1981(81.3)$ & \\
\hline Black & 3495 (15.6) & $374(15.4)$ & & $322(13.2)$ & $374(15.4)$ & \\
\hline Others/Unknown & $1003(4.5)$ & $81(3.3)$ & & $95(3.9)$ & $81(3.3)$ & \\
\hline Gender & & & 0.032 & & & 0.964 \\
\hline Male & $18,032(80.6)$ & 2007 (82.4) & & 2028 (83.3) & 2007 (82.4) & \\
\hline Female & $4344(19.4)$ & $429(17.6)$ & & $408(16.7)$ & $429(17.6)$ & \\
\hline Marital status & & & $<.001$ & & & 0.158 \\
\hline Single & $4511(20.2)$ & $330(13.5)$ & & $366(15.0)$ & $330(13.5)$ & \\
\hline Married & $11,093(49.6)$ & $1309(53.7)$ & & $1260(51.7)$ & $1309(53.7)$ & \\
\hline Others status $^{a}$ & $5591(25.0)$ & $641(26.3)$ & & $675(27.7)$ & $641(26.3)$ & \\
\hline Unknown & $1181(5.3)$ & $156(6.4)$ & & $135(5.5)$ & $156(6.4)$ & \\
\hline Grade & & & 0.546 & & & 0.170 \\
\hline Grade I & $2992(13.4)$ & $319(13.1)$ & & $323(13.3)$ & $319(13.1)$ & \\
\hline Grade ॥ & $10,175(45.5)$ & $1071(44.0)$ & & $1082(44.4)$ & $1071(44.0)$ & \\
\hline Grade III & 3919 (17.5) & $448(18.4)$ & & 387 (15.9) & $448(18.4)$ & \\
\hline Grade IV & $164(0.7)$ & $17(0.7)$ & & $21(0.9)$ & $17(0.7)$ & \\
\hline Unknown & $5126(22.9)$ & 581 (23.9) & & $623(25.6)$ & $581(23.9)$ & \\
\hline AJCC stage & & & $<.001$ & & & 0.402 \\
\hline 1 & 7257 (32.4) & $974(40.0)$ & & 971 (39.9) & $974(40.0)$ & \\
\hline$\|$ & 3411 (15.2) & $347(14.2)$ & & $392(16.1)$ & $347(14.2)$ & \\
\hline III & $3616(16.2)$ & $393(16.1)$ & & $365(15.0)$ & $393(16.1)$ & \\
\hline IV & 6529 (29.2) & $537(22.0)$ & & $532(21.8)$ & $537(22.0)$ & \\
\hline Unknown & $1563(7.0)$ & $185(7.6)$ & & $176(7.2)$ & 185 (7.6) & \\
\hline Surgery & & & 0.012 & & & 0.460 \\
\hline No/unknown & $14,355(64.2)$ & 1500 (61.6) & & 1525 (62.6) & 1500 (61.6) & \\
\hline Yes & 8021 (35.8) & $936(38.4)$ & & 911 (37.4) & $936(38.4)$ & \\
\hline Chemotherapy & & & $<.001$ & & & 0.413 \\
\hline No/unknown & $14,809(66.2)$ & $1868(76.7)$ & & $804(33.0)$ & 831 (34.1) & \\
\hline Yes & 7567 (33.8) & $568(23.3)$ & & $1632(67.0)$ & 1605 (65.9) & \\
\hline Radiotherapy & & & $<.001$ & & & 0.683 \\
\hline No/unknown & $5723(25.6)$ & 831 (34.1) & & $1880(77.2)$ & $1868(76.7)$ & \\
\hline Yes & $16,653(74.4)$ & 1605 (65.9) & & $556(22.8)$ & 568 (23.3) & \\
\hline
\end{tabular}

a other status including divorced, widowed, separated or domestic partner

married status and treatment modalities like surgery and radiotherapy were protective factors for LCSM of patients with prior cancer history (Table 4).

Subgroup analyses were further performed to compare the OS and LCSM of larynx cancer patients with or without prior cancer history. As shown in Fig. 5a, a prior cancer history was significantly associated with shorter OS in most subgroups, except in patients with younger age $(<45)$, non-white race or higher histological grade (III-IV). However, regarding to LCSM, a prior cancer 
Table 3 Distributions of prior cancer types

\begin{tabular}{lll}
\hline Prior cancer type & Number & Proportion (\%) \\
\hline Prostate & 865 & $35.5 \%$ \\
Lung and Bronchus & 252 & $10.3 \%$ \\
Urinary Bladder & 164 & $6.7 \%$ \\
Breast & 138 & $5.7 \%$ \\
Larynx & 105 & $4.3 \%$ \\
Colon & 103 & $4.2 \%$ \\
Kidney and Renal pelvis & 65 & $2.7 \%$ \\
Tongue & 64 & $2.6 \%$ \\
Melanoma of the skin & 59 & $2.4 \%$ \\
Others site & 621 & $25.5 \%$ \\
\hline
\end{tabular}

history tended to act as a protective factor in most subgroups (Fig. 5b).

\section{Discussion}

The current study focused on the impact of a prior cancer history on clinical outcomes among patients with larynx cancer. The findings of this study may provide implications for the exclusion criteria of relevant clinical trials. In our study, $9.8 \%$ of patients had exactly one prior cancer before the diagnosis of larynx cancer. The median time interval between larynx cancer and prior cancers was 5.3 years in this cohort, longer than several previously reported cancers [13, 19]. Prostate cancer, lung and bronchial cancer, urinary bladder cancer and breast cancer were the most prevalent types of prior cancer in the larynx cohort, of which the histologic distribution was different from other cancer types, such as breast cancer [19], lung cancer [16] and nasopharyngeal cancer [13]. The high proportion of prior prostate or breast cancer history in our cohort and other reported cohort suggests its high prevalence in the US general population $[7,13,16]$. In addition, the lung and bronchial cancer or urinary cancer, such as bladder and kidney, were closely related to smoking, which was also the leading cause of larynx cancer [20].

In modern clinical practice, patients previously diagnosed with cancers are often excluded in most of clinical trials due to the assumption that a prior cancer might impact the survival outcomes. This stringent eligibility criteria might hinder clinical trial enrollment of a substantial number of patients, thus limiting generalizability, extending trial durations, and leading to a premature trial termination, especially amongst rare malignancies with low incidence $[14,21]$. Recently, several studies have reported that a prior cancer history might not

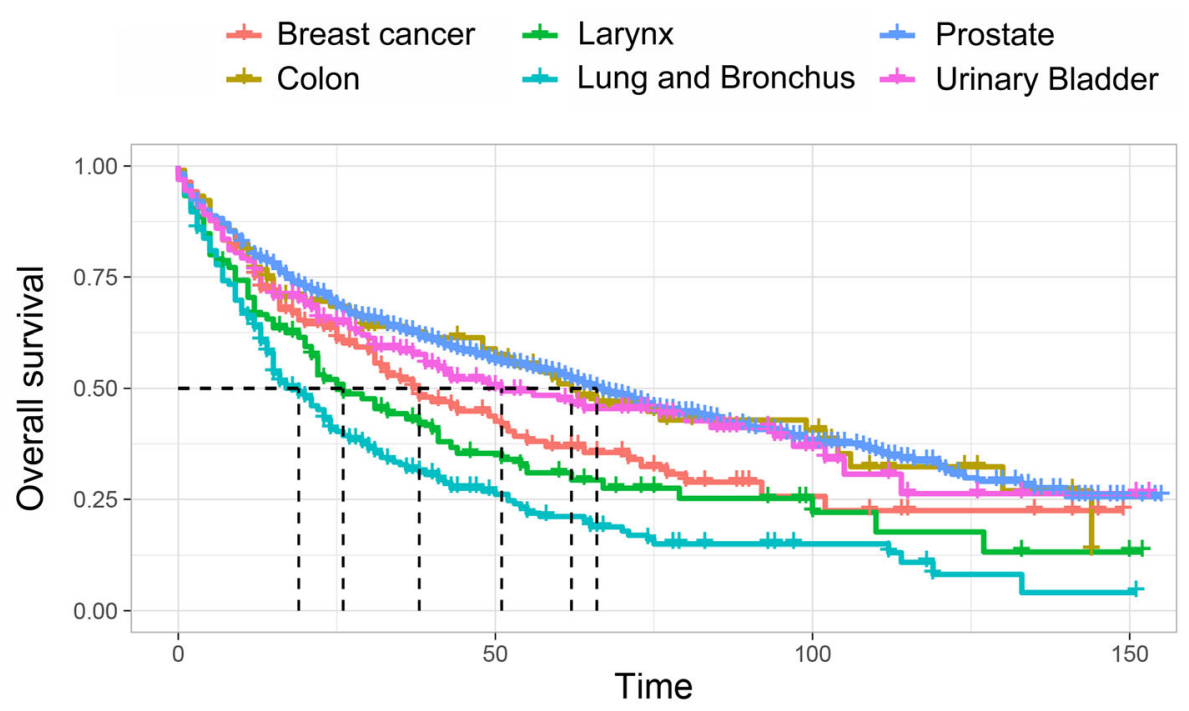

Number at risk

\begin{tabular}{|c|cccc|}
\hline 138 & 39 & & 8 & 0 \\
103 & 47 & 18 & 0 \\
105 & 26 & 8 & 2 \\
252 & 38 & & 8 & 1 \\
865 & 331 & & 100 & 4 \\
164 & 56 & & 14 & 3 \\
\hline 0 & 50 & Time & 100 & 150 \\
\hline
\end{tabular}

Fig. 1 The overall survival (OS) of larynx cancer patient with different types of prior cancer 


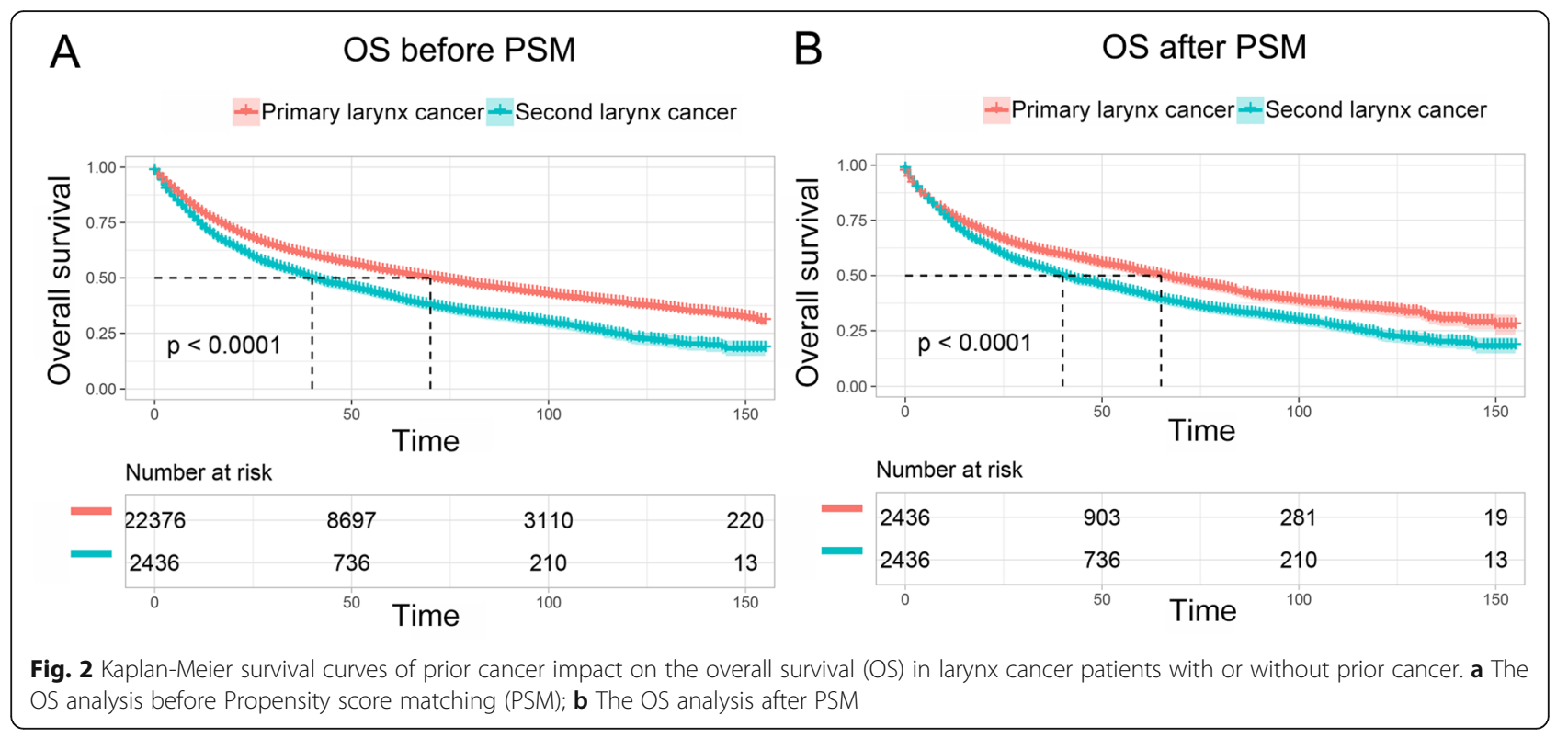

adversely affect patients' survival who suffered a subsequent cancer. For example, a previous retrospective study by Laccetti et al. reported that a prior cancer history did not adversely affect clinical outcomes of patients with advanced lung cancer, regardless of the different stages or types of prior cancer [16]. Another study also suggested that the prognosis of patients with uterine papillary serous carcinoma was not affected by prior breast cancer and tamoxifen exposure [17]. However, the impact of a prior cancer history on patients with larynx cancer has yet to be extensively studied.

In the present study, we found that a prior cancer history adversely impacted the overall survival of larynx cancer patients but seemed to be associated with a decreased larynx cancer-specific mortality. Interestingly, when stratified by timing of prior cancer, we found that

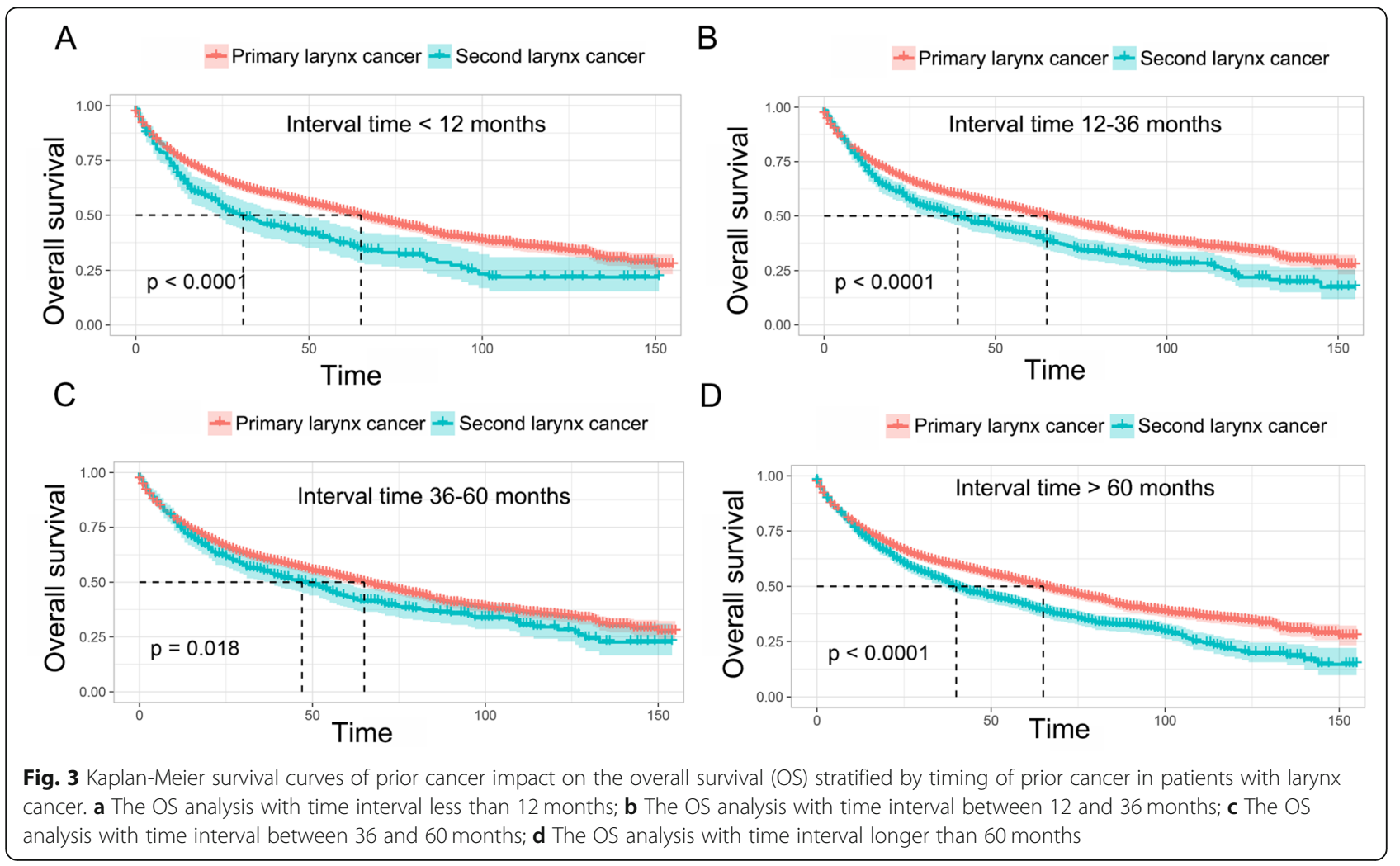




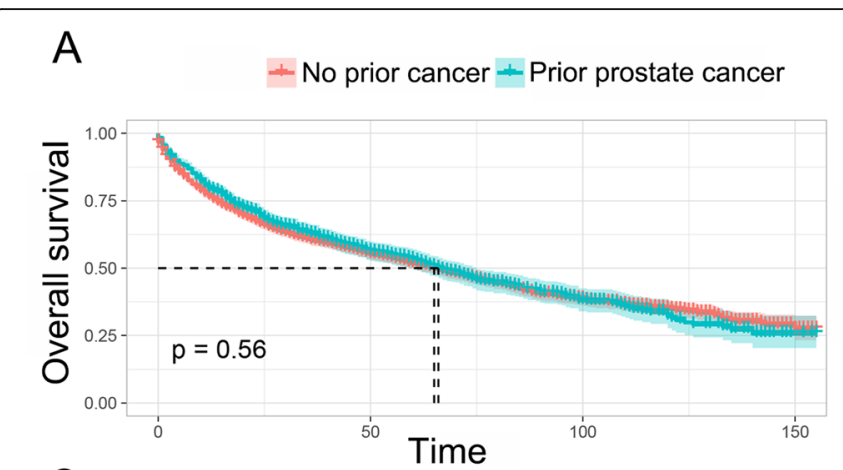

C
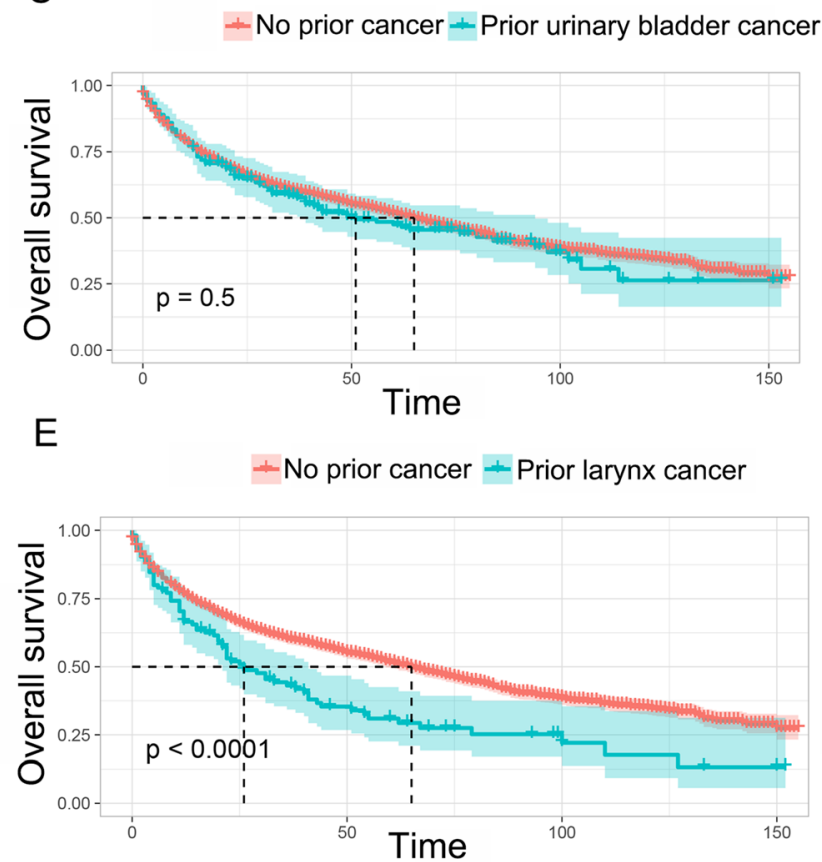

B

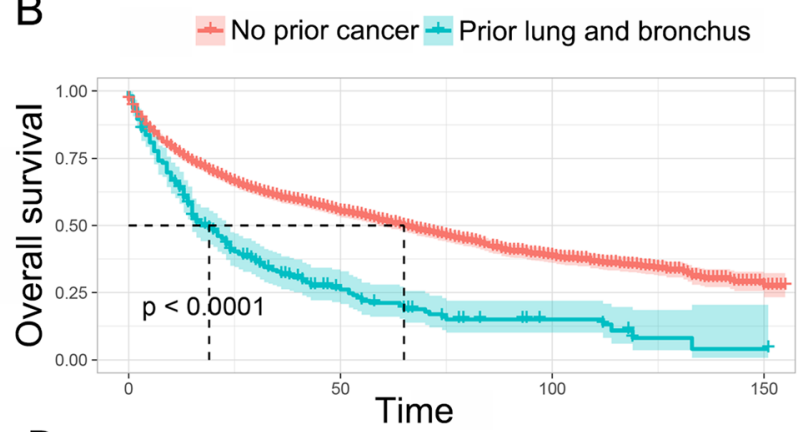

$\mathrm{D}$

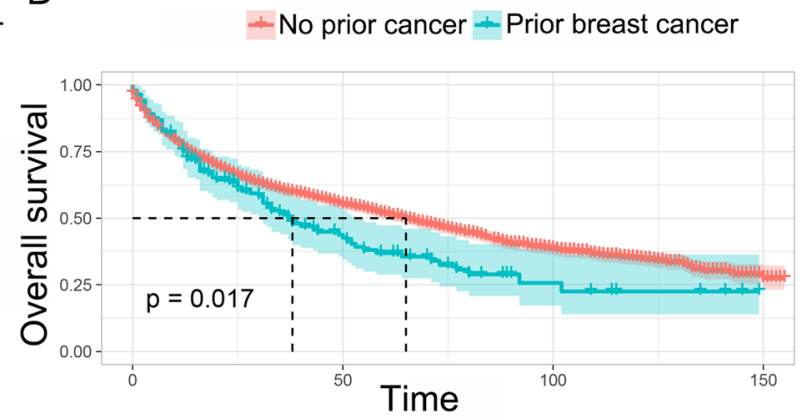

$\mathrm{F}$

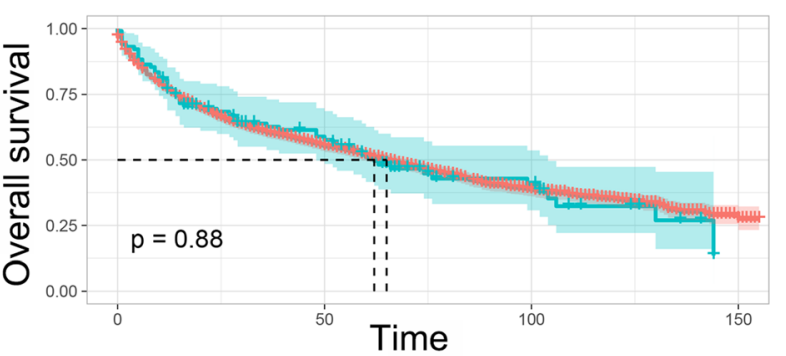

Fig. 4 Kaplan-Meier survival curves of prior cancer impact on the overall survival (OS) stratified by different types of prior cancer in patients with larynx cancer. a The impact of prior prostate cancer on OS; $\mathbf{b}$ The impact of prior lung and bronchus cancer on OS; $\mathbf{c}$ The impact of prior urinary bladder cancer on OS; $\mathbf{d}$ The impact of prior breast cancer on OS; e The impact of prior larynx cancer on OS; $\mathbf{f}$ The impact of prior colon cancer on OS

the positive effect on larynx cancer-specific mortality was gradually increased when the time interval was longer than 12 months. This could be potentially explained by the early diagnosis due to regular follow-up examinations or reduced exposure to risk factors such as tobacco. Our results also indicated that the impact of prior cancer on the OS and LCSM of larynx cancer patients varies distinctly across different cancer types. An inferior overall survival was observed in larynx cancer survivors with prior lung, breast or larynx cancer, but not prostate, bladder or colon cancers. In addition, a possible decreased larynx cancer-specific mortality was observed within prostate cancer survivors. Hence, it seems cancers with excellent prognoses, such as prostate or bladder cancer, had no substantial impact on the clinical outcome of subsequent larynx cancer, primarily because of its indolent course, early diagnosis, and favorable response to local treatment [16]. These findings inspired us that certain types of prior cancer could be considered in clinical trials regarding to larynx cancer patients.

The multivariate Cox analysis indicated that patients with prior cancer had inferior overall survival than those without prior cancer. Subsequently, the subgroup analyses further indicated that only patients with younger age $(<45)$, non-Caucasians or higher histological grade (III-IV) did not have inferior survival as compared to patients with no prior cancer. Those results were, however, not consistent with several studies reporting a nonadverse or even positive impact a prior cancer history has on the OS amongst patients with other types of malignancies [16, 22-24]. Together with the subgroup analysis based on the timing and types of prior cancer, larynx cancer patients with prior cancers should be prudently considered for clinical trials. 
Table 4 Comprehensive multivariable-adjusted Hazard Ratios for overall survival and larynx cancer-specific mortality

\begin{tabular}{|c|c|c|c|c|}
\hline \multirow[t]{2}{*}{ Characteristic } & \multicolumn{2}{|l|}{ Overall survival } & \multicolumn{2}{|c|}{ Larynx cancer-specific mortality } \\
\hline & AHR (95\% Cl) & $P$ value & AHR $(95 \% \mathrm{Cl})$ & $P$ value \\
\hline \multicolumn{5}{|l|}{ All patient after PSM } \\
\hline Primary larynx cancer & 1.0 (Ref) & & 1.0 (Ref) & \\
\hline Second larynx cancer & $1.30(1.21-1.41)$ & $<.001$ & $0.83(0.72-0.94)$ & 0.004 \\
\hline \multicolumn{5}{|c|}{ Subgroup with prior cancer } \\
\hline \multicolumn{5}{|l|}{ Age } \\
\hline$<45$ & 1.0 (Ref) & & 1.0 (Ref) & \\
\hline $45-64$ & $1.12(0.53-2.39)$ & 0.765 & $2.98(0.39-22.6)$ & 0.290 \\
\hline$>64$ & $1.60(0.76-3.38)$ & 0.216 & $3.86(0.51-29.3)$ & 0.190 \\
\hline \multicolumn{5}{|l|}{ Gender } \\
\hline Male & 1.0 (Ref) & & 1.0 (Ref) & \\
\hline Female & $0.89(0.78-1.03)$ & 0.111 & $0.85(0.65-1.10)$ & 0.210 \\
\hline \multicolumn{5}{|l|}{ Race } \\
\hline White & 1.0 (Ref) & & 1.0 (Ref) & \\
\hline Black & $0.99(0.87-1.15)$ & 0.986 & $1.15(0.89-1.48)$ & 0.290 \\
\hline Others/Unknown & $0.81(0.60-1.09)$ & 0.164 & $1.43(0.93-2.22)$ & 0.110 \\
\hline \multicolumn{5}{|l|}{ Marital status } \\
\hline Single & 1.0 (Ref) & & 1.0 (Ref) & \\
\hline Married & $0.73(0.62-0.85)$ & $<.001$ & $0.75(0.56-0.98)$ & 0.040 \\
\hline Other status ${ }^{a}$ & $1.09(0.92-1.29)$ & 0.303 & $1.03(0.77-1.40)$ & 0.830 \\
\hline Unknown & $0.79(0.61-1.02)$ & 0.072 & $0.59(0.35-1.01)$ & 0.053 \\
\hline \multicolumn{5}{|l|}{ AJCC stage } \\
\hline I & 1.0 (Ref) & & 1.0 (Ref) & \\
\hline$\|$ & $1.73(1.46-2.05)$ & $<.001$ & 2.00 (1.39-2.88) & $<.001$ \\
\hline III & $2.58(2.19-3.05)$ & $<.001$ & $3.22(2.29-4.54)$ & $<.001$ \\
\hline IV & $3.95(3.37-4.63)$ & $<.001$ & $5.23(3.80-7.19)$ & $<.001$ \\
\hline Unknown & 1.59 (1.28-1.97) & $<.001$ & $2.57(1.70-3.88)$ & $<.001$ \\
\hline \multicolumn{5}{|l|}{ Histological grade } \\
\hline Grade I & 1.0 (Ref) & & 1.0 (Ref) & \\
\hline Grade II & $1.04(0.87-1.24)$ & 0.665 & $1.06(0.75-1.50)$ & 0.760 \\
\hline Grade III & $1.19(0.98-1.44)$ & 0.085 & $1.05(0.72-1.52)$ & 0.820 \\
\hline Grade IV & $2.42(1.39-4.20)$ & 0.002 & $0.94(0.28-3.23)$ & 0.920 \\
\hline Unknown & $1.12(0.93-1.35)$ & 0.238 & $0.98(0.67-1.41)$ & 0.890 \\
\hline \multicolumn{5}{|l|}{ Surgery } \\
\hline No surgery & 1.0 (Ref) & & 1.0 (Ref) & \\
\hline Surgery & $0.57(0.50-0.64)$ & $<.001$ & $0.68(0.54-0.85)$ & $<.001$ \\
\hline \multicolumn{5}{|l|}{ Chemotherapy } \\
\hline No chemotherapy & 1.0 (Ref) & & 1.0 (Ref) & \\
\hline Chemotherapy & $0.82(0.71-0.95)$ & 0.006 & $0.94(0.73-1.20)$ & 0.610 \\
\hline \multicolumn{5}{|l|}{ Radiotherapy } \\
\hline No radiation & 1.0 (Ref) & & 1.0 (Ref) & \\
\hline Radiation & $0.56(0.49-0.63)$ & $<.001$ & $0.67(0.56-0.88)$ & 0.002 \\
\hline
\end{tabular}




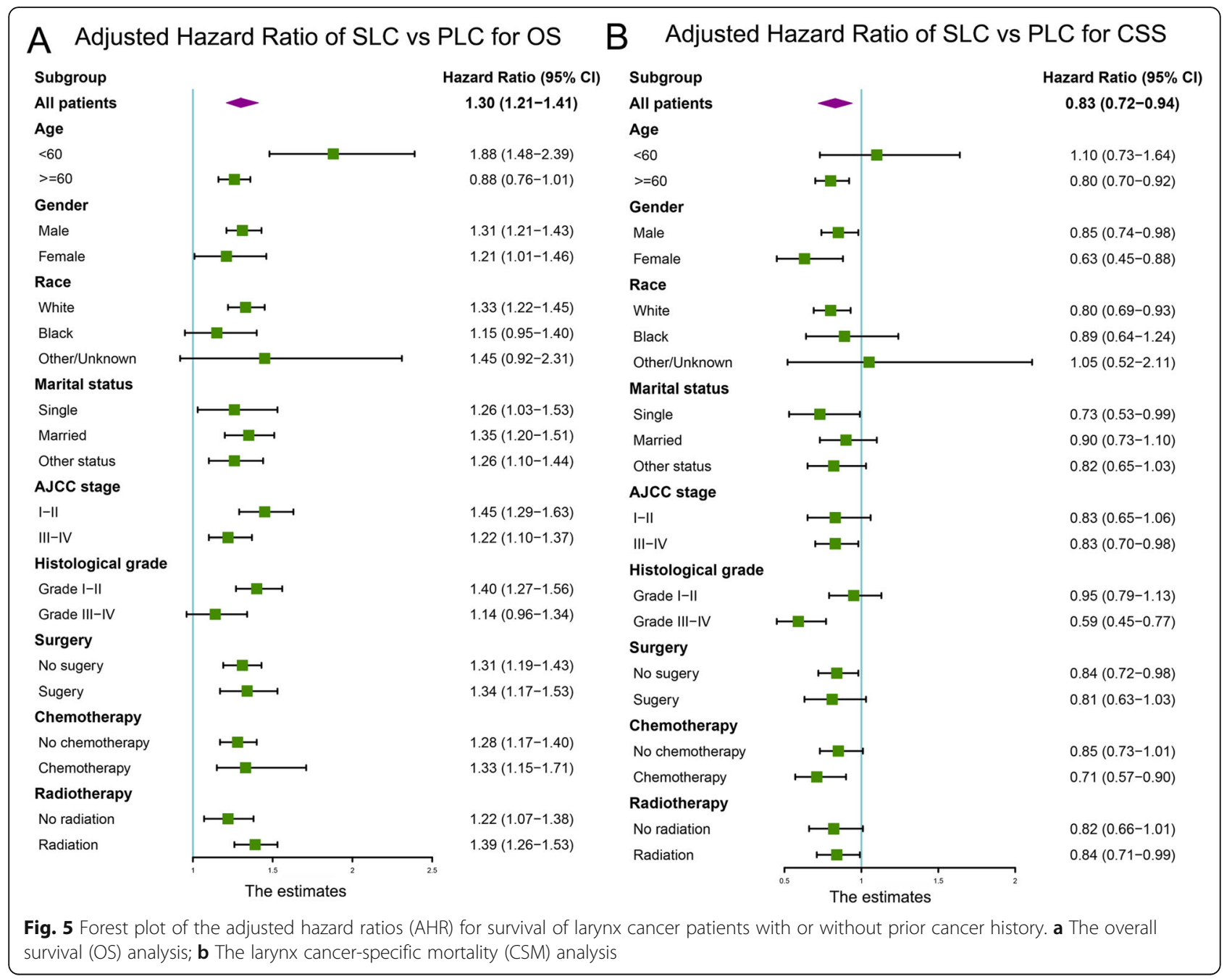

Interestingly, the multivariate Fine and Gray's regression analysis showed a decreased larynx cancer-specific mortality in patients with prior cancer as compared to those without a prior history of cancer. This result echoes earlier findings concentrating on other site [13, $25,26]$, indicating that patients with prior history of cancer had a dramatically increased risk for death from prior cancer or other non-cancer cause compared to those without prior cancer. These risks should be carefully considered in the treatment toward subsequent larynx cancer occurring in such patients with prior history of cancer. The subgroup analysis further found that a prior cancer history could exhibit a protective factors for larynx cancer-specific mortality especially in patients with older age, white race, single status, later AJCC stage, higher histological grade, receiving no surgery, and receiving chemotherapy or radiotherapy. Potential explanations includes individualized patient's biology and treatment response, or more frequent engagement in healthcare systems.
Previous epidemiological data highlighted large racial disparities in survival of patients with many cancer types $[27,28]$, which might due to many confounding socioeconomical and behavioral factors, such as diet, smoking, alcohol abuse, and access to screening and treatment. Inconsistently, no survival difference was observed among patients with different race in our study. Moreover, various studies yielded conflicting results about the impact of marital status on survival of cancer patients, with protective [29, 30], mixed [31, 32], or nonsignificant [33, 34] effects identified. Most of these investigations involved a single malignancy. In our study, as supplementary, both the multivariate Cox survival analysis and the Fine and Gray's regression analysis showed that a married status served as a protective factor for prognosis of patients with prior cancer history. Either financial or psychological support from family could be important contributing factors.

There are several limitations to our study. Firstly, some valuable information such as comorbidities and 
the toxicity of treatment on prior cancer were unavailable in the SEER database. Secondly, our study is limited by the intrinsic weaknesses of retrospective databases wherein selection bias is inherent. We believe that all the observed results in our study should be prospectively validated.

\section{Conclusion}

In summary, patients with prior cancer history had inferior overall survival but decreased larynx cancerspecific mortality in comparison with those without prior cancer. These impacts varied across patients with different timing, prior cancer types and clinicopathologic features. Except for a few particular prior cancer, clinical trials should be considered prudently for laryngeal cancer patients with prior cancers.

\section{Supplementary Information}

The online version contains supplementary material available at https://doi. org/10.1186/s12885-020-07634-2.

Additional file 1: Figure S1. The flowchart of case selection.

Additional file 2: Figure S2. Histogram of standardized differences before and after PSM. (A) Raw larynx cancer patients with prior cancer; (B) Matched larynx cancer patients with prior cancer; (C) Raw larynx cancer patients without prior cancer; (B) Matched larynx cancer patients without prior cancer.

Additional file 3: Figure S3. Cumulative incidence curves of prior cancer impact on the larynx cancer-specific mortality (LCSM) of larynx cancer patients with or without prior cancer. (A) The LCSM analysis before Propensity score matching (PSM); (B) The LCSM analysis after PSM. The solid line represents LCSM and the dotted line represents non-LCSM.

Additional file 4: Figure S4. Cumulative incidence curves of larynx cancer-specific mortality (LCSM) of larynx cancer patients stratified by timing of prior cancer. (A) The LCSM analysis with time interval less than 12 months; (B) The LCSM analysis with time interval between 12 and 36 months; (C) The LCSM analysis with time interval between 36 and 60 months; (D) The LCSM analysis with time interval longer than 60 months. The solid line represents LCSM and the dotted line represents non-LCSM.

Additional file 5: Figure S5. Cumulative incidence curves of larynx cancer-specific mortality (LCSM) of larynx cancer patients stratified by different types of prior cancer. (A) The impact of prior prostate cancer on LCSM; (B) The impact of prior lung and bronchus cancer on LCSM; (C) The impact of prior urinary bladder cancer on LCSM; (D) The impact of prior breast cancer on LCSM; (E) The impact of prior larynx cancer on LCSM; (F) The impact of prior colon cancer on LCSM. The solid line represents LCSM and the dotted line represents non-LCSM.

Additional file 6 .

\section{Abbreviations}

SEER: Surveillance, Epidemiology, and End Results; OS: overall survival; CSS: cancer-specific survival; PSM: Propensity score matching; AHR: Adjusted hazard ratio; IQR: Interquartile range

\section{Acknowledgements}

The authors acknowledged the efforts of the Surveillance, Epidemiology, and End Results (SEER) Program tumor registries in the creation of the SEER database.

\section{Authors' contributions}

$K Z, X R$ conceived and designed the present study. $K Z, X R, R L, Z Z$ and $H C$ analyzed the data, $K Z$ interpreted the data and wrote the manuscript. All authors read and approved the final manuscript.

\section{Funding}

This work was financially supported by the Grants LY19H130001 from Zhejiang Provincial Natural Science Foundation of China.

\section{Availability of data and materials}

The datasets generated and/or analysed during the current study are available in the Surveillance, Epidemiology, and End Results Program repository, https://seer.cancer.gov/data/.

\section{Ethics approval and consent to participate}

All analyses of human data conducted in this study were approved by the Institutional Review Board of The First Affiliated Hospital of Wenzhou Medical University and in accordance with the ethical standards of the institutional and/or national research committee and with the 1964 Helsinki declaration and its later amendments or comparable ethical standards. Informed consent was exempted because of the retrospective nature of this study. All authors signed authorization forms and received permission from SEER to access and use the dataset.

\section{Consent for publication}

Not applicable.

\section{Competing interests}

The authors declare that they have no competing interests.

Received: 20 July 2020 Accepted: 12 November 2020

Published online: 23 November 2020

\section{References}

1. Jemal A, Bray F, Center MM, Ferlay J, Ward E, Forman D. Global cancer statistics. CA Cancer J Clin. 2011;61(2):69-90.

2. de Moor JS, Mariotto AB, Parry C, Alfano CM, Padgett L, Kent EE, Forsythe L, Scoppa S, Hachey M, Rowland JH. Cancer survivors in the United States: prevalence across the survivorship trajectory and implications for care. Cancer Epidemiol Biomarkers Prev. 2013;22(4):561-70.

3. Miller KD, Siegel RL, Lin CC, Mariotto AB, Kramer JL, Rowland JH, Stein KD, Alteri R, Jemal A. Cancer treatment and survivorship statistics, 2016. CA Cancer J Clin. 2016;66(4):271-89.

4. Hayat MJ, Howlader N, Reichman ME, Edwards BK. Cancer statistics, trends, and multiple primary cancer analyses from the surveillance, epidemiology, and end results (SEER) program. Oncologist. 2007;12(1):20-37.

5. Wood ME, Vogel V, Ng A, Foxhall L, Goodwin P, Travis LB. Second malignant neoplasms: assessment and strategies for risk reduction. J Clin Oncol. 2012; 30(30):3734-45.

6. Youlden DR, Baade PD. The relative risk of second primary cancers in Queensland, Australia: a retrospective cohort study. BMC Cancer. 2011;11:83.

7. Siegel RL, Miller KD, Jemal A. Cancer statistics, 2018. CA Cancer J Clin. 2018; 68(1):7-30.

8. Wolf GT, Fisher SG, Hong WK, Hillman R, Spaulding M, Laramore GE, Endicott JW, McClatchey K, Henderson WG. Induction chemotherapy plus radiation compared with surgery plus radiation in patients with advanced laryngeal cancer. N Engl J Med. 1991;324(24):1685-90.

9. Strieth S, Ernst BP, Both I, Hirth D, Pfisterer LN, Künzel J, Eder K. Randomized controlled single-blinded clinical trial of functional voice outcome after vascular targeting KTP laser microsurgery of early laryngeal cancer. Head Neck. 2019;41(4):899-907.

10. Zhang Y, Wang B, Sun G, Zhang G, Lu L, Liang G. Carbon dioxide laser microsurgery versus low-temperature plasma radiofrequency ablation for T1a Glottic Cancer: a single-blind randomized clinical trial. Biomed Res Int. 2018;2018:4295960.

11. Huang PW, Lin CY, Hsieh CH, Hsu CL, Fan KH, Huang SF, Liao CT, Ng SK, Yen TC, Chang JT, et al. A phase II randomized trial comparing neoadjuvant chemotherapy followed by concurrent chemoradiotherapy versus concurrent chemoradiotherapy alone in advanced squamous cell carcinoma of the pharynx or larynx. Biom J. 2018;41(2):129-36.

12. Kodaira T, Kagami $Y$, Shibata $T$, Shikama N, Nishimura $Y$, Ishikura $S$, Nakamura K, Saito Y, Matsumoto Y, Teshima T, et al. Results of a multi-institutional, randomized, non-inferiority, phase III trial of accelerated fractionation versus standard fractionation in radiation therapy for T1-2N0M0 glottic cancer: Japan clinical oncology group study (JCOG0701). Ann Oncol. 2018;29(4):992-7. 
13. Wang YQ, Lv JW, Tang LL, Du XJ, Chen L, Li WF, Liu X, Guo Y, Lin $\mathrm{AH}$, Mao YP, et al. Effect of prior cancer on trial eligibility and treatment outcomes in nasopharyngeal carcinoma: implications for clinical trial accrual. Oral Oncol. 2019;90:23-9.

14. Filion M, Forget G, Brochu O, Provencher L, Desbiens C, Doyle C, Poirier B, DuRocher M, Camden S, Lemieux J. Eligibility criteria in randomized phase $\mathrm{II}$ and III adjuvant and neoadjuvant breast cancer trials: not a significant barrier to enrollment. Clin Trials (London, England). 2012;9(5):652-9.

15. Gerber DE, Laccetti AL, Xuan L, Halm EA, Pruitt SL. Impact of prior cancer on eligibility for lung cancer clinical trials. J Natl Cancer Inst. 2014;106(11).

16. Laccetti AL, Pruitt SL, Xuan L, Halm EA, Gerber DE. Effect of prior cancer on outcomes in advanced lung cancer: implications for clinical trial eligibility and accrual. J Natl Cancer Inst. 2015;107(4).

17. Pierce SR, Stine JE, Gehrig PA, Havrilesky LJ, Secord AA, Nakayama J, Snavely AC, Moore DT, Kim KH. Prior breast cancer and tamoxifen exposure does not influence outcomes in women with uterine papillary serous carcinoma. Gynecol Oncol. 2017;144(3):531-5.

18. Cronin KA, Ries LA, Edwards BK. The surveillance, epidemiology, and end results (SEER) program of the National Cancer Institute. Cancer. 2014; 120(Suppl 23):3755-7.

19. Ji F, Yang CQ, Li XL, Zhang LL, Yang M, Li JQ, Gao HF, Zhu T, Cheng MY, Li WP, et al. Risk of breast cancer-related death in women with a prior cancer. Aging. 2020;12(7):5894-906.

20. Sasco AJ, Secretan MB, Straif K. Tobacco smoking and cancer: a brief review of recent epidemiological evidence. Lung Cancer (Amsterdam, Netherlands). 2004;45 Suppl 2:S3-9.

21. Lemieux J, Goodwin PJ, Pritchard KI, Gelmon KA, Bordeleau L, Duchesne T, Camden S, Speers $\mathrm{CH}$. Identification of cancer care and protocol characteristics associated with recruitment in breast cancer clinical trials. J Clin Oncol. 2008;26(27):4458-65.

22. Pandurengan RK, Dumont AG, Araujo DM, Ludwig JA, Ravi V, Patel S, Garber J, Benjamin RS, Strom SS, Trent JC. Survival of patients with multiple primary malignancies: a study of 783 patients with gastrointestinal stromal tumor. Ann Oncol. 2010;21(10):2107-11.

23. Varty PP, Delrio P, Boulos PB. Survival in colorectal carcinoma associated with previous extracolonic cancer. Ann R Coll Surg Engl. 1994;76(3):180-4.

24. Al-Husseini MJ, Saad AM, Turk T, Tabash MA, Abdel-Rahman O. Impact of Prior Malignancy on Survival Outcomes of Stage IV Pancreatic Adenocarcinoma: SEER-Based Cohort. J Gastrointest Cancer. 2019;50(4):794-800.

25. Pulte D, Gondos A, Brenner H. Long-term survival of patients diagnosed with non-Hodgkin lymphoma after a previous malignancy. Leukemia Lymphoma. 2009;50(2):179-86.

26. Laccetti AL, Pruitt SL, Xuan L, Halm EA, Gerber DE. Prior cancer does not adversely affect survival in locally advanced lung cancer: A national SEER-medicare analysis. Lung Cancer (Amsterdam, Netherlands). 2016;98:106-13.

27. Özdemir BC, Dotto GP. Racial differences in Cancer susceptibility and survival: more than the color of the skin? Trends Cancer. 2017;3(3):181-97.

28. DeSantis CE, Siegel RL, Sauer AG, Miller KD, Fedewa SA, Alcaraz Kl, Jemal A. Cancer statistics for African Americans, 2016: Progress and opportunities in reducing racial disparities. CA Cancer J Clin. 2016;66(4):290-308.

29. Aizer AA, Chen MH, McCarthy EP, Mendu ML, Koo S, Wilhite TJ, Graham PL, Choueiri TK, Hoffman KE, Martin NE, et al. Marital status and survival in patients with cancer. J Clin Oncol. 2013;31(31):3869-76.

30. Osborne C, Ostir GV, Du X, Peek MK, Goodwin JS. The influence of marital status on the stage at diagnosis, treatment, and survival of older women with breast cancer. Breast Cancer Res Treat. 2005;93(1):41-7.

31. Nelles JL, Joseph SA, Konety BR. The impact of marriage on bladder cancer mortality. Urol Oncol. 2009;27(3):263-7.

32. Goodwin JS, Hunt WC, Key CR, Samet JM. The effect of marital status on stage, treatment, and survival of cancer patients. Jama. 1987;258(21):3125-30.

33. Greenberg ER, Chute CG, Stukel T, Baron JA, Freeman DH, Yates J, Korson R. Social and economic factors in the choice of lung cancer treatment. A population-based study in two rural states. N Engl J Med. 1988;318(10):612-7.

34. Jatoi A, Novotny P, Cassivi S, Clark MM, Midthun D, Patten CA, Sloan J, Yang $P$. Does marital status impact survival and quality of life in patients with non-small cell lung cancer? Observations from the mayo clinic lung cancer cohort. Oncologist. 2007;12(12):1456-63.

\section{Publisher's Note}

Springer Nature remains neutral with regard to jurisdictional claims in published maps and institutional affiliations.

\section{Ready to submit your research? Choose BMC and benefit from:}

- fast, convenient online submission

- thorough peer review by experienced researchers in your field

- rapid publication on acceptance

- support for research data, including large and complex data types

- gold Open Access which fosters wider collaboration and increased citations

- maximum visibility for your research: over $100 \mathrm{M}$ website views per year

At BMC, research is always in progress.

Learn more biomedcentral.com/submissions 